\title{
PRESENÇA DE CONTEÚDOS DE SEMÂNTICA EM LIVROS DIDÁTICOS PARA ENSINO MÉDIO
}

\author{
Aléxia Islabão dos Santos ${ }^{1}$ \\ Kleber Eckert ${ }^{2}$
}

\begin{abstract}
Resumo: Através do presente trabalho, realiza-se uma análise da coleção de livros didáticos para Ensino Médio intitulada Português: Linguagens (CEREJA; MAGALHÂES, 2005) com o objetivo de demonstrar como são abordados os conteúdos da "semântica". A metodologia deste trabalho consistiu na leitura dos subcapítulos de cada livro pertencente a essa coleção e na descriçáo da forma como os conteúdos citados são abordados por ela. Como auxílio, também foi elaborado um roteiro que serviu como base para a análise de cada subcapítulo. Além disso, foi realizada uma fundamentação teórica utilizando como embasamento autores da área, como Cançado (2018), Pietroforte e Lopes (2014), Geraldi e Ilari (2006), entre outros. Como resultados, pode-se destacar a análise detalhada da forma como esses livros didáticos abordam de maneira teórica e prática conceitos como sinonímia, antonímia, campo semântico, hiponímia, hiperonímia, polissemia, ambiguidade e pronomes demonstrativos abordados na perspectiva dêitica. Além de uma análise geral da forma como a coleção introduz, desenvolve e organiza seus conteúdos.
\end{abstract}

Palavras-chave: Coleção de livros didáticos. Conteúdos. Semântica. Análise.

\section{THE PRESENCE OF CONTENTS OF SEMANTIC IN HIGH SCHOOL TEXTBOOKS}

\begin{abstract}
Through the present work, an analysis of the collection of textbooks for High School entitled Portuguese: Languages (CEREJA; MAGALHÂES, 2005) is carried out in order to demonstrate how the contents of "semantics" are approached. The methodology of this work consisted of reading the sub-chapters of each book belonging to that collection and describing the way in which the contents cited are approached by it. As an aid, a script was also prepared that served as a basis for the analysis of each subchapter. In addition, a theoretical basis was made using as a basis authors from the area
\end{abstract}

1 Graduanda em Letras - Português pelo Instituto Federal de Educação, Ciência e Tecnologia do Rio Grande do Sul (IFRS) - Campus Bento Gonçalves. Email: alexiaislabao@gmail.com

2 Doutor em Letras pela Universidade de Caxias do Sul (UCS) e professor do Instituto Federal de Educação, Ciência e Tecnologia do Rio Grande do Sul (IFRS) - Campus Bento Gonçalves. Email: kleber.eckert@bento.ifrs.edu.br 
such as Cançado (2018), Pietroforte and Lopes (2014), Geraldi and Ilari (2006), among others. As a result, we can highlight the detailed analysis of how these textbooks approach in a theoretical and practical way concepts such as synonymy, antonymia, semantic field, hyponymy, hyperonymy, polysemy, ambiguity and demonstrative pronouns addressed in the deitic perspective. In addition to a general analysis of how the collection introduces, develops and organizes its contents.

Keywords: Collection of textbooks. Contents. Semantics. Analysis.

\section{Introduçáo}

O presente trabalho tem por objetivo realizar uma análise sobre uma coleção de livros didáticos para Ensino Médio, a fim de avaliar a presença de conteúdos relacionados ao tópico "semântica" nesses livros. Para isso, foi selecionada a coleção de livros "Português: Linguagens", de William Roberto Cereja e Thereza Cochar Magalháes, publicada em 2005. Nessa coleção, verificou-se que o livro destinado à primeira série do Ensino Médio contém um capítulo inteiro designado aos tópicos de semântica. Já no livro destinado à segunda série, há apenas a parte dos pronomes demonstrativos abordados na perspectiva dêitica. No livro destinado à terceira série, encontram-se vários subcapítulos intitulados "Semântica e Interação", que permeiam diferentes capítulos do livro. A escolha dessa coleção deve-se ao fato de ela apresentar vários tópicos relevantes para a semântica.

Para a escrita deste artigo, primeiro foram examinadas diferentes coleções de livros didáticos, até chegar à escolha da coleção citada. Então, os livros pertencentes a essa coleção foram examinados de forma superficial, a fim de identificar os conteúdos de semântica neles abordados. Através dos sumários dos livros didáticos selecionados para a análise, foram identificados vários subcapítulos que fazem parte da semântica. São eles: "Sinonímia e Antonímia"; "Campo Semântico, Hiponímia e Hiperonímia"; "Polissemia"; e "Ambiguidade", todos separados em subcapítulos diferentes, dentro do mesmo capítulo intitulado "Introdução à Semântica" no livro de primeira série. Depois, o subcapítulo "Pronomes Demonstrativos", no livro de segunda série, que se relaciona à semântica se analisado sob a perspectiva da dêixis. E também o subcapítulo "Semântica e Interação", que permeia diferentes capítulos do livro de terceira série e dos outros dois livros da coleção.

Após isso, foi desenvolvida uma fundamentação teórica capaz de abranger todos os tópicos de semântica trabalhados por esses livros didáticos. $\mathrm{Na}$ fundamentação teórica, esses tópicos são descritos e explicados de forma breve e objetiva com base em autores da área. Dessa forma, garante-se que o leitor seja previamente apresentado aos assuntos que seráo vistos na sequência durante a análise. A análise de cada livro didático deu-se através da leitura atenta dos capítulos selecionados e da descrição de suas abordagens de conteúdo e exercícios, utilizando como base um roteiro previamente elaborado e anexado a este trabalho.

Para garantir a organização e a devida separação de cada assunto, os títulos deste artigo estão divididos de modo a representar o livro de cada série e seus subcapítulos, conforme são apresentados. $\mathrm{Na}$ análise, estabelece-se uma relação entre a forma como o conteúdo é trabalhado pelo livro didático e a fundamentaçáo 
teórica apresentada inicialmente. Ao final, apresentam-se as consideraçôes finais obtidas com a análise da coleção escolhida, as referências utilizadas na elaboração deste trabalho e o roteiro utilizado como auxiliar na análise dos livros didáticos.

\section{Fundamentaçáo Teórica}

De acordo com Cançado (2018, p. 18), a semântica é o ramo da Linguística que se volta para a investigação do significado das sentenças. Mas a autora afirma que o sistema semântico nem sempre é o único responsável pelo significado. Por exemplo, alguns aspectos do significado são explicados através das intençôes dos falantes, ou seja, dentro de circunstâncias de uso da língua. Quando se trata do uso da língua, no meio acadêmico fala-se em pragmática. Semântica e pragmática andam juntas e a própria autora afirma que distingui-las não é uma tarefa simples. Este artigo não foca nessa distinção, mas, devido ao seu objetivo, é importante que se apresente um embasamento sobre o que tratam esses dois termos.

Um dos tópicos presentes nos estudos da semântica é o da sinonímia e da antonímia. Segundo Pietroforte e Lopes (2014, p. 126), dois termos são chamados de sinônimos quando apresentam a possibilidade de substituírem um ao outro conforme determinados contextos. Por exemplo, as palavras "novo" e "jovem" são sinônimas quando utilizadas no contexto "homem jovem / homem novo". Porém, esses mesmos autores afirmam que não existem sinônimos perfeitos. Por exemplo, "novo" e "jovem" não são sinônimas quando utilizadas em um contexto semelhante a "livro novo / livro jovem". Portanto, é possível dizer que o falante pode criar ou desfazer sinonímias através do seu contexto de fala. Além disso, os autores ainda completam que, mesmo em casos em que dois termos possam ser substituídos no mesmo contexto, eles não são sinônimos perfeitos, porque as condiçôes do seu emprego na fala são distintas. Por exemplo, o uso das palavras "amar" ou "adorar" muda a intensidade do sentimento que se deseja exprimir. Cançado $(2018$, p. 48), resume essas ideias ao afirmar que "não é possível pensar em sinonímia de palavras fora do contexto em que estas são empregadas".

$\mathrm{Na}$ antonímia ocorre o contrário da sinonímia, uma vez que nela realizamse os significados contrários (LOPES; PIETROFORTE, 2014). Pietroforte e Lopes (2014, p. 127) explicam que, "assim como não existe semelhança total de sentido entre sinônimos, não há oposição absoluta entre antônimos". Para Cançado (2018, p 52), definir antonímia como uma simples oposiçáo de sentidos entre as palavras não é o suficiente. Essa autora delimita três tipos básicos de antonímia: a binária ou complementar, que são pares de palavras que, quando uma é aplicada, a outra necessariamente náo pode ser aplicada, ou seja, a negaçáo de uma implica a afirmação de outra (por exemplo: morto/vivo, móvel/imóvel, igual/diferente); a inversa, que ocorre quando uma palavra descreve a relação entre duas coisas ou pessoas e uma outra palavra descreve essa mesma relação, mas em uma ordem inversa (por exemplo: pai/filho); e a gradativa, quando as duas palavras estão em terminais opostos de uma escala contínua de valores, nesse caso a negação de um termo não 
implica a afirmaçáo do outro, pois permite um meio termo (por exemplo: quente/ frio [morno], alto/baixo [médio]).

Na semântica também encontram-se tópicos referentes ao campo semântico, hiponímia e hiperonímia. O primeiro, Lopes e Pietroforte (2014) definem como uma série que comporta palavras de pelo menos um traço em comum com as demais e também ao menos um traço que as diferencia. As duas últimas, esses mesmos autores definem como sendo "fenômenos derivados das disposiçóes hierárquicas de classificação próprias do sistema lexical” (LOPES; PIETROFORTE, 2014, p. 128). A taxionomia animal das ciências biológicas é um exemplo perfeito para se explorar essas duas questôes porque permite estabelecer diversas relaçôes de hierarquia. Por exemplo: a relação entre Animal $\rightarrow$ Mamífero $\rightarrow$ Felino. Felino é hipônimo de Mamífero. Mamífero é hiperônimo de Felino, mas é hipônimo de Animal. Animal é hiperônimo de Mamífero. Ao analisar esse exemplo, com base em Cançado (2018, p. 32), é possível ver que o item lexical mais específico (felino), que contém todas as outras propriedades da cadeia (é um animal e é um mamífero), é chamado de hipônimo. O item lexical que está contido nos outros itens lexicais, mas não contém nenhuma das outras propriedades da cadeia, portanto o termo mais geral (animal), é chamado de hiperônimo.

Outro tópico relevante refere-se ao conceito de polissemia. Uma palavra é polissêmica quando é possível atribuir mais de um significado a uma mesma palavra, conforme explicam Pietroforte e Lopes (2014, p. 131). Cançado (2018, p. 73) ainda acrescenta que esses diferentes significados da mesma palavra têm alguma relação entre si. Dessa forma, um exemplo de polissemia é a palavra "folha", que pode significar uma folha de árvore ou uma folha de papel. Esses dois tipos de folhas possuem uma relação entre seus significados, o que permite a classificação dessa palavra como polissêmica.

Com relação à duplicidade de significados, também se estuda o conceito de ambiguidade. Existem diferentes motivos que podem tornar uma sentença ambígua, o que acarreta em diferentes tipos de ambiguidade (ECKERT, 2019): ambiguidade lexical (por causa dos diferentes significados possíveis de serem compreendidos por uma mesma palavra, o que abrange mas não se restringe à ideia de polissemia vista anteriormente); ambiguidade sintática (a dupla interpretação é gerada pela forma como a sentença é estruturada); ambiguidade de escopo (de acordo com Müller e Viotti (2014), envolve as relaçóes de escopo, em que a interpretação de uma expressão depende da interpretação de outra); ambiguidade por correferência (a qual termo determinado pronome se refere); e ambiguidade por atribuição de papéis temáticos (quem é o agente ou o paciente da ação).

Além disso, os pronomes demonstrativos também se enquadram no campo da semântica quando analisados sob a perspectiva da dêixis, que pode ser compreendida como o ato de mostrar. Ilari e Geraldi (2006, p. 66) afirmam que os pronomes demonstrativos vêm acompanhados de um gesto de apontar e, portanto, são chamados pela linguística moderna de dêiticos, ou seja, palavras que mostram. De acordo com Cançado (2018, p. 60), "os elementos dêiticos permitem 
identificar pessoas, coisas, momentos e lugares a partir da situação da fala, ou seja, a partir do contexto". No entanto, é necessário distinguir o fenômeno da dêixis do fenômeno da anáfora. Segundo Cançado (2018, p. 61), "a anáfora também consiste em identificar objetos, pessoas, momentos, lugares e açóes; entretanto, isso se dá por uma referência a outros objetos, pessoas etc., anteriormente mencionados no discurso ou na sentença”. Portanto, quando uma expressão está retomando algo já mencionado, diz-se que essa expressão é anafórica.

\section{Análise da Coleção}

Os próximos títulos apresentam, separadamente, cada um dos três livros didáticos pertencentes à coleção selecionada. Dentro deles, encontram-se subtítulos que representam cada subcapítulo analisado, conforme são apresentados no próprio livro.

\subsection{Primeira Série}

O primeiro livro analisado destina-se à primeira série do Ensino Médio. Nesse livro, há um capítulo inteiro destinado aos tópicos de semântica, intitulado "Introdução à Semântica". Esse capítulo conta com diferentes subcapítulos que abrangem os tópicos de sinonímia e antonímia, campo semântico, hiponímia e hiperonímia, polissemia e ambiguidade. Nos subtítulos a seguir, encontra-se a análise feita sobre a introduçáo desse capítulo e cada um de seus subcapítulos.

\subsubsection{Introdução do Capítulo}

Antes de entrar no primeiro subcapítulo, que se refere aos conteúdos de sinonímia e antonímia, o capítulo "Introdução à Semântica" propóe seis exercícios iniciais. Esses exercícios estimulam os alunos a refletirem sobre o significado das palavras através da análise e comparação de frases. O título que precede os exercícios está nomeado como "construindo o conceito". A partir desse título, compreende-se que os exercícios propostos são uma forma de introduzir os alunos aos estudos da semântica antes de apresentar aspectos teóricos.

O primeiro exercício do capítulo apresenta uma tirinha em que uma palavra da fala de um dos personagens está sublinhada. As perguntas envolvendo essa tira estimulam o aluno a pensar sobre o significado dessa palavra destacada, levando em consideraçáo o contexto apresentado. $\mathrm{O}$ segundo exercício leva o aluno a refletir sobre a relação entre o significado de palavras diferentes. Por exemplo, a relação existente entre os grupos de palavras "homem - mulher - criança" e "carneiro ovelha - cordeiro". O terceiro exercício incita os alunos a refletirem sobre uma situação em que a troca de uma expressão por outra diferente pode ocasionar alteração de significado. Por exemplo, trocar a expressão "duas pessoas" pela expressão "um homem e uma mulher", uma vez que nem sempre essa troca é viável.

O quarto exercício aponta a diferença entre a utilização dos verbos "ser" e "estar" e estimula os alunos a justificar se as frases dadas como exemplo são aceitáveis 
na Língua Portuguesa. O quinto exercício demonstra a diferença de educação e respeito no tratamento com pessoas através do uso de determinadas palavras em comparação a outras. Por exemplo, a diferença entre dizer "eu mandei fazer" e "eu pedi que fizesse". O sexto e último exercício mostra a impossibilidade de se utilizar sinônimos em certas ocasióes. Por exemplo, os sinônimos "cachorro" e "cáo" não podem substituir um ao outro em uma expressão como "cachorro-quente" para "cão-quente". Esse último exercício é condizente com o próximo subcapítulo a ser abordado, pois evidencia a questão da sinonímia.

Após esses exercícios, o capítulo traz um novo título nomeado "conceituando", em que apresenta uma pequena conceituação sobre semântica. Nela, afirma-se que as palavras possuem significados que podem variar, dependendo do contexto em que são empregadas. Na sequência, aparece um pequeno quadro colorido e centralizado, recurso visual padrão que o livro utiliza para destacar a definição dos termos estudados. Nesse quadro, define-se o termo "semântica" como: "a parte da gramática que estuda os aspectos relacionados ao sentido de palavras e enunciados" (CEREJA; MAGALHÃES, 2005a, p. 128). Ao final, citam-se os nomes de cada subcapítulo contido nesse capítulo para informar quais são alguns dos aspectos tratados pela semântica. Dessa forma termina a introduçáo do capítulo e começa o subcapítulo "Sinonímia e Antonímia".

\subsubsection{Sinonímia e Antonímia}

Nesse subcapítulo, frases utilizadas nos exercícios de introduçáo anteriores, como a expressão "cão-quente" e a substituição da expressão "homem e mulher" por "duas pessoas", são retomadas com um pouco mais de aprofundamento. Depois disso, apresenta-se um quadro com a seguinte definição: "sinônimos são palavras de sentidos aproximados que podem ser substituídas uma pela outra em diferentes contextos" (CEREJA; MAGALHÂES, 2005a, p. 129, grifo nosso). Nota-se que se fala em sentidos aproximados, não idênticos. Essa noção é melhor desenvolvida em seguida quando o livro afirma, tal qual abordado na fundamentação teórica, que não existem sinônimos perfeitos. Para exemplificar essa afirmação, utiliza-se o exemplo das palavras "furto" e "roubo", que apesar de utilizadas como sinônimos em situaçôes gerais, possuem suas próprias especificidades na linguagem jurídica.

$\mathrm{Na}$ sequência, para introduzir a parte da antonímia, apresenta-se uma tira que fala em "esquerda" e "direita". A definição de antônimos dada pelo livro é breve: "Antônimos são palavras de sentidos contrários entre si" (CEREJA; MAGALHÃES, 2005a, p. 129). Na explicação teórica, comenta-se que a ocorrência de um par de antônimos perfeitos também é difícil e que em alguns casos é mais adequado falar em graus de antonímia. Para exemplificar isso, apresentam-se os pares de antônimos "velho - novo" e "bom - mau" e salienta-se que a avaliação desses pares é subjetiva: um objeto pode ser mais velho ou menos velho; uma pessoa pode ser mais boa ou menos boa. No livro, ainda se cita um caso curioso e interessante de antonímia, o par "emigrante - imigrante". Sobre esse par, o livro deixa a seguinte questáo em aberto: no momento em que o emigrante chega a outro país, ele náo passa a se 
tornar um imigrante? Não há exercícios nesse subcapítulo, apenas explicações. Sendo assim, o capítulo termina após essa questão.

\subsubsection{Campo Semântico, Hiponímia e Hiperonímia}

Entre todos os subcapítulos analisados, esse é o menor, pois ocupa apenas o espaço de um terço de uma página. Suas explicaçôes são extremamente breves. Ainda assim, é possível relacionar o seu conteúdo com o que foi previamente discutido na fundamentação teórica deste trabalho, pois aborda-se a questão de sentido amplo e sentido específico dos hiperônimos e hipônimos. Logo no início, pede-se que se leia a seguinte frase: "comprou um computador, um monitor, um teclado e uma impressora para o escritório, pois, sem esse equipamento, não conseguiria dar conta do trabalho." (CEREJA; MAGALHÁES, 2005a, p. 130). A escolha por apresentar essa frase é interessante, pois nela é possível trabalhar os três conceitos que nomeiam o subcapítulo tratado ao mesmo tempo.

Após a frase indicada, há um parágrafo apenas de explicação. Nele, afirmase que as palavras "computador", "monitor", "teclado" e "impressora" apresentam familiaridade de significados pois pertencem ao mesmo campo semântico: o universo da informática. Também se afirma que a palavra "equipamento" é uma palavra de significado amplo que engloba as outras; portanto, "equipamento" é o hiperônimo, e "computador", "monitor", "teclado" e "impressora" são hipônimos. $\mathrm{Na}$ sequência dessa explicação, aparece um quadro em que se apresenta a definição dos termos "hipônimo" e "hiperônimo": "são palavras pertencentes a um mesmo campo semântico, sendo o hipônimo uma palavra de sentido mais específico e o hiperônimo uma palavra de sentido mais genérico." (CEREJA; MAGALHÁES, 2005a, p. 130). Com essa última definição, o subcapítulo termina.

\subsubsection{Polissemia}

Logo no início desse subcapítulo, pede-se que o aluno compare o seguinte par de frases: "não consigo passar o fio de lá na agulha de tricô" e "enrosquei minha pipa no fio daquele poste" (CEREJA; MAGALHĀES, 2005a, p. 130, grifo do autor). A palavra "fio" é propositalmente grifada para que o aluno possa perceber os diferentes significados que ela recebe em cada uma das frases. Na sequência, apresenta-se uma explicação que esclarece essa diferença: o primeiro é um fio de fibra e o segundo é um fio de cabo de aço. Nessa explicação, também se demonstra o que há de comum entre esses dois significados: sequência, fiada, eixo, alinhamento e encadeamento. Então, afirma-se que quando uma única palavra apresenta mais de um significado, ela é chamada de polissêmica. Após essa explicação, aparece um quadro que define o termo polissemia como: "a propriedade que uma palavra tem de apresentar vários sentidos." (CEREJA; MAGALHÁES, 2005a, p. 130). Destaca-se que essa definição se assemelha ao previamente abordado pela fundamentação teórica.

Após essa breve introdução, que ocupa cerca de um terço da página, seguem sete exercícios. $\mathrm{O}$ primeiro exercício apresenta uma lista de palavras para significar 
dinheiro e uma lista de palavras para significar beneficiários e pede que o aluno identifique a relação entre as duas listas. Por exemplo: mesada - filhos; salário empregado; lucro - comerciante; entre outras. O segundo exercício pede que o aluno cite palavras que ele conheça de linguagem popular usadas para significar dinheiro. Nesse exercício, as respostas são pessoais de cada aluno. O terceiro exercício segue uma lógica similar à do anterior. Nele, pede-se que o aluno cite diferentes palavras que ele conheça de linguagem popular que são usadas para designar o diabo.

O quarto exercício apresenta uma tirinha e informa que o humor da tira se constrói a partir do uso de palavras antônimas. Nesse caso, nota-se que o exercício está retomando um tópico que foi abordado em um subcapítulo anterior. Depois da tira, pede-se que o aluno responda: quais são as palavras antônimas usadas na tira; que tipo de características o significado dessas palavras indica; e como o humor da tira se justifica. O quinto exercício pede que seja feita uma comparação entre duas frases: "Rubens e Márcia estão se separando, você sabia?" e "Rubens está se separando de Márcia, você sabia?" (CEREJA; MAGALHÃES, 2005a, p. 131). Nesse exercício, pede-se que se diga qual é a diferença de significado que os dois enunciados apresentam e que hipóteses podem ser levantadas sobre essa alteração de significado. Destaca-se que esse exercício remete ao tópico de ambiguidade, pois em "Rubens e Márcia estáo se separando" há uma duplicidade de significados: Rubens e Márcia estão separando-se um do outro ou de seus respectivos cônjuges? A ambiguidade ainda não foi abordada pelo capítulo.

O sexto exercício apresenta três grupos de palavras e em cada grupo há uma palavra que náo pertence ao mesmo campo semântico das outras. Nesse exercício, pede-se que o aluno identifique a palavra destoante e diga qual é o hiperônimo de cada grupo. O sétimo exercício apresenta outra tirinha. No contexto da tira, a palavra engavetamento pode ter dois significados: congestionamento de trânsito ou ser atingido por uma gaveta. Entáo, pede-se que o aluno diga qual é o significado da palavra "engavetamento" se considerada apenas a parte verbal e qual é o seu significado se considerado o contexto apresentado pela tira. É possível perceber que, apesar de estarem dentro do subcapítulo de polissemia, os exercícios não trabalham somente esse tópico. Eles também abordam os tópicos de sinonímia, antonímia, campo semântico, hiponímia e hiperonímia. Assuntos pertencentes a subcapítulos que já foram estudados e que não apresentavam exercícios, eram constituídos apenas por teoria. O tipo de exercício que predomina nessa listagem é o que estimula o aluno a pensar em palavras diferentes para o mesmo significado ou refletir sobre o significado das palavras em geral. O subcapítulo termina com esses exercícios.

\subsubsection{Ambiguidade}

O subcapítulo inicia com a apresentação de uma tirinha. Nela, um pterodátilo age como se fosse um cuco saindo de um relógio enquanto alguém comenta que o relógio está atrasado. Após a tirinha, explica-se o motivo que leva a palavra "atrasado" a ser ambígua (atrasado em relação às horas do relógio e atrasado em relação ao pássaro do período jurássico) e causar humor dentro do contexto da tira. 
Na sequência, o termo ambiguidade é definido como: "a duplicidade de sentidos que pode haver em um texto, verbal ou não verbal.” (CEREJA; MAGALHÃES, 2005a, p. 132). Depois do quadro de definição, comenta-se que o uso da ambiguidade pode ou não ser proposital. Afirma-se que, quando usada intencionalmente, ela pode ser um importante recurso de expressão, mas, se usada involuntariamente, ela pode provocar falhas na comunicação. Com isso, o subcapítulo divide-se em dois títulos menores nomeados "a ambiguidade como recurso de construção" e "a ambiguidade como problema de construção", em que se exemplifica a afirmaçáo anterior.

O título que aborda a ambiguidade como recurso de construção apresenta apenas duas frases. Nele, informa-se que a ambiguidade é usada como recurso em textos poéticos, publicitários, humorísticos, quadrinhos e anedotas, de forma a tornar a comunicação mais direta, descontraída e divertida. $\mathrm{O}$ título que aborda a ambiguidade como um problema de construçáo ocupa meia página; portanto, é um pouco mais extenso que o anterior. Nele, apresenta-se uma frase ambígua que comprova a falha na comunicaçáo: "durante o jogo, Lúcio deu várias caneladas em Guilherme. Depois entrou o Marcelo no jogo e ele levou vários empurrôes e pontapés" (CEREJA; MAGALHÃES, 2005a, p. 132). Sobre essa frase, comentase que alguém que náo tenha assistido a essa partida de futebol terá dificuldade para compreender qual informação está sendo passada: quem levou empurrôes e pontapés? Nas explicaçóes que sucedem esse exemplo, é estabelecida uma comparação entre a linguagem oral e escrita. Afirma-se que a linguagem oral conta com mais recursos para tornar o sentido preciso do que a linguagem escrita, que conta apenas com as palavras. Por esse motivo, para que os textos tenham clareza e precisão, o livro recomenda o emprego adequado das palavras.

Após essa parte teórica, são propostos cinco exercícios. O primeiro deles apresenta uma frase ambígua extraída de um texto da revista Veja. Então, pede-se que o aluno identifique qual é a ambiguidade e refaça o trecho procurando desfazêla. O segundo exercício apresenta outra frase extraída da revista Veja: "O que faz uma boa metrópole" (CEREJA; MAGALHÁES, 2005a, p. 133). Nele, pede-se que o aluno reescreva essa frase de duas formas diferentes a fim de deixar bem claro os dois significados permitidos por ela. $\mathrm{O}$ terceiro exercício apresenta duas frases ambíguas e pede que o aluno as reescreva de modo a desfazer a ambiguidade. $\mathrm{O}$ quarto exercício, extraído de um vestibular da UNICAMP, apresenta um trecho que possui uma frase ambígua. Sobre esse trecho, pede-se que o aluno: identifique qual é a passagem com ambiguidade; transcreva-a; aponte quais são as duas interpretaçóes possíveis; e explique o que a torna estruturalmente ambígua. $\mathrm{O}$ quinto exercício, também da UNICAMP, apresenta um trecho de jornal que, pela forma como foi escrito, permite um efeito de humor. Pede-se que o aluno transcreva a passagem em que se encontra esse efeito e explique qual situação engraçada essa passagem permite imaginar. Depois, pede-se que o aluno reescreva o trecho de forma a eliminar essa interpretação humorística.

Diferente dos exercícios propostos no subcapítulo "Polissemia", os exercícios vistos acima não fazem uma revisão de subcapítulos anteriores. Todos os exercícios 
acima giram em torno do tópico do próprio subcapítulo a que pertencem: a ambiguidade. Através deles, os alunos precisam identificar as diferenças de significado causadas por frases ambíguas e tentar encontrar soluçóes que evitem essas situaçóes. Portanto, eles são estimulados a refletirem sobre os assuntos recém abordados pela parte teórica. Os conteúdos de ambiguidade tratados pelo livro relacionam-se aos já abordados na fundamentação teórica deste trabalho, no que se refere à duplicidade de sentidos. Porém, no livro, a classificação da ambiguidade em diferentes tipos não é abordada em nenhum momento.

Após os exercícios, há um novo título dentro do subcapítulo nomeado "a ambiguidade na construção do texto". Esse título inicia com um poema curto, de Arnaldo Antunes, apresentado ao lado de uma imagem do planeta Terra. Em seguida, são propostos mais três exercícios. No primeiro exercício, apresentamse os significados de uma palavra que aparece no poema conforme ela consta no dicionário. Entáo, pede-se que o aluno identifique qual verso do poema aproxima essa palavra de seu sentido literal e qual verso quebra esse sentido literal e gera ambiguidade. No segundo exercício, pede-se que o aluno associe o poema à imagem que o acompanha, a fim de levantar hipóteses sobre novos significados que podem ser dados a determinada palavra a partir dessa imagem. No terceiro exercício, pergunta-se sobre o conteúdo do poema. Nesses três últimos exercícios, é possível notar um foco maior na interpretação de texto.

\subsection{Segunda Série}

O segundo livro analisado destina-se à segunda série do Ensino Médio. Nesse livro, destaca-se o subcapítulo "Pronomes Demonstrativos", uma vez que esse assunto também está relacionado aos estudos da semântica. Esse subcapítulo encontra-se dentro do capítulo "O Pronome", que abrange os pronomes pessoais, de tratamento, possessivos, demonstrativos, indefinidos, interrogativos e relativos, exatamente nessa ordem. No subtítulo a seguir, encontra-se a análise feita sobre o subcapítulo destacado.

\subsubsection{Pronomes Demonstrativos}

No início do capítulo, pede-se que se leia uma tirinha em que um personagem com um disco de vinil na máo pergunta "o que é isto?". O outro personagem, um pouco mais distante, começa a responder "isso é...". Entáo, logo após a tira, começam as explicaçôes sobre os pronomes demonstrativos. $\mathrm{Na}$ explicação, ressaltase que o primeiro personagem, ao falar de algo que está segurando em suas mãos, usa a palavra "isto". Já o segundo personagem, ao falar de algo que está longe de si, mas próximo de quem está falando, usa a palavra "isso". Essa perspectiva observada no contexto da tira está relacionada ao fenômeno da dêixis, já mencionado durante a fundamentação teórica. Depois dessa explicação, informa-se que as palavras "isto" e "isso" são pronomes demonstrativos e apresenta-se a definição desse termo: "são aqueles que situam pessoas ou coisas em relação às três pessoas do discurso. Essa 
localização pode se dar no tempo, no espaço ou no próprio texto." (CEREJA; MAGALHÂES, 2005b, p. 93).

$\mathrm{Na}$ sequência, um breve parágrafo aborda a diferença entre pronomes demonstrativos substantivos e pronomes demonstrativos adjetivos. Segundo o livro, o primeiro funciona como um substantivo e o segundo acompanha um substantivo. Depois, apresenta-se uma tabela que reúne os pronomes demonstrativos variáveis (por gênero e número) e invariáveis referentes às três pessoas do discurso. No livro, afirma-se: "para empregar os pronomes demonstrativos adequadamente, é necessário considerar as pessoas do discurso e aquilo que se fala ou se escreve." (CEREJA; MAGALHÃES, 2005b, p. 94). Dessa forma, dividem-se os exemplos da utilização desses pronomes em três títulos diferentes: "em relação ao espaço", "em relação ao tempo" e "em relação ao falado ou escrito ou ao que se vai falar ou escrever".

No primeiro e no segundo caso, as explicaçôes e exemplos são apenas dêiticos. No primeiro, indica-se a proximidade ou a distância de quem fala ou ouve em relação ao que se está falando. No segundo, indica-se a proximidade ou distância no tempo: presente, passado, um tempo distante, entre outros. No terceiro caso, as explicaçôes e os exemplos apresentam os pronomes como um recurso para introduzir ou retomar elementos do texto, de forma a funcionar como anáforas ou catáforas. Portanto, embora o subcapítulo tenha iniciado através de uma perspectiva dêitica com sua tira introdutória, no seu desenvolvimento apresentam-se exemplos do uso dos pronomes que podem ser considerados recursos de coesão textual. Dessa forma, nota-se que o livro aborda essas duas possibilidades separadamente, porém sem identificá-las com sua nomenclatura específica.

Depois dos aspectos teóricos, o subcapítulo propõe quatro exercícios. O primeiro exercício apresenta uma tirinha em que se usa um pronome possessivo na fala dos personagens. Então, pede-se que os alunos identifiquem o pronome e informem se ele é adjetivo ou substantivo. Esse exercício faz uma revisão do subcapítulo anterior, que trata dos pronomes possessivos, mas não apresenta exercícios. Na sequência, apresenta-se outra tirinha e informa-se que ela servirá como base para as próximas duas questôes. Então, no segundo exercício, pedese que o aluno identifique o uso de um pronome de tratamento na fala dos personagens da tira. O subcapítulo sobre pronomes de tratamento também foi visto anteriormente. No terceiro exercício, há três perguntas, separadas pelas letras $\mathrm{a}, \mathrm{b}$ e c, sobre o pronome possessivo "dele" também citado na tira. A letra "a" pergunta qual pronome pode substituir "dele" no contexto da tira mantendo o mesmo valor semântico. A letra "b" pergunta por que o personagem usa o pronome "dele" no lugar do pronome resposta da pergunta anterior. A letra "c" pergunta por que o pronome "dele" está entre aspas na tira, o que se refere ao significado pretendido pelo personagem.

O quarto exercício apresenta dois anúncios e pede que o aluno compare o emprego do pronome demonstrativo nos dois. Duas perguntas acompanham os anúncios, separadas pelas letras a e b. Na letra "a", pergunta-se se o pronome demonstrativo se refere a algo já dito ou a uma imagem sobre a qual ainda se vai 
falar ou já se falou. É interessante notar que esse é um exercício de identificação de anáfora ou catáfora. $\mathrm{Na}$ letra "b", pede-se que, considerando a resposta anterior, o aluno responda se os pronomes demonstrativos estão empregados de acordo com a variedade padráo da língua e entáo justifique sua resposta. Com esses exercícios, o aluno é estimulado a refletir sobre as noções já vistas pela teoria. Através deles, o aluno precisa comparar o uso de diferentes pronomes para uma mesma situação ou do mesmo pronome com objetivos diferentes: retomar algo já mencionado ou apresentar uma informação nova. Além disso, ele também precisa refletir sobre o porquê da utilização de um determinado pronome em relação a outros também possíveis para o mesmo contexto, dependendo dos significados pretendidos pelo falante. Esse último caso relaciona-se aos conceitos de pragmática abordados pela fundamentação teórica.

\subsection{Terceira Série}

O terceiro livro analisado destina-se à terceira série do Ensino Médio. Nesse livro, a presença de conteúdos relacionados ao campo da semântica é consideravelmente menor em comparaçáo aos dois primeiros analisados. Para esse livro, destaca-se o subcapítulo "Semântica e Interação". Esse subcapítulo permeia vários capítulos diferentes da obra e aproxima conteúdos diversos com os estudos da semântica. No subtítulo a seguir, encontra-se uma análise ampla sobre a presença desse subcapítulo no livro.

\subsubsection{Semântica e Interaçáo}

No livro destinado à terceira série do Ensino Médio, o subcapítulo "Semântica e Interaçáo" aparece em nove capítulos diferentes, sendo eles: "Período Composto por Subordinação: As Orações Substantivas"; "Período Composto por Subordinação: As Orações Adjetivas"; "Período Composto por Subordinação: As Oraçôes Subordinadas Adverbiais"; "Período Composto por Coordenação: As Oraçōes Coordenadas"; "A Pontuação"; "Concordância. Concordância Verbal"; "Concordância Nominal"; "Regência Verbal e Nominal"; e "A Colocação Pronominal". Esses subcapítulos complementam seu respectivo capítulo através de exercícios que envolvem a análise de significados e utilizam como base os assuntos recentemente abordados. São pequenos e não apresentam nenhuma parte destinada à teoria, sendo constituídos apenas por esses exercícios.

Para exemplificar, foram selecionados dois exemplos de exercícios contidos nesses subcapítulos. Nesse caso, analisou-se a "Semântica e Interação" do capítulo "Período Composto por Subordinação: As Oraçôes Adjetivas". Um dos exercícios contidos nela estimula a troca da oração por um adjetivo com valor semântico similar. Por exemplo, substituir a oração "que não se pode definir" por "indefinível". Outro exercício, nesse mesmo capítulo, pede que se analise a diferença de significado de uma frase, dependendo da forma como se utilizam as vírgulas. Por exemplo, a diferença de significado entre as frases "os pensionistas que recebem seu contracheque no dia $1^{\circ}$ terão atendimento especial nesta agência bancária" e "os 
pensionistas, que recebem seu contracheque no dia $1^{\circ}$, teráo atendimento especial nesta agência bancária" (CEREJA; MAGALHÃES, 2005c, p. 84). Portanto, esses subcapítulos não abordam especificamente tópicos da semântica, mas tratam de valor semântico, ou seja, do significado.

\section{Consideraçóes Finais}

Após a análise individual de cada livro, foi elaborada uma tabela, a fim de sintetizar os aspectos gerais observados na coleção selecionada. Nessa tabela, foram avaliados os seguintes critérios: introdução e desenvolvimento dos conteúdos; organização dos conteúdos; exercícios propostos; linguagem; e relação com a fundamentação teórica. Cada um desses critérios foi analisado a partir de impressões pessoais. Eles foram classificados como: "excelente", "bom", "regular" ou "ruim". Em adição a isso, também foram deixadas observaçôes sobre cada avaliação.

Tabela 1: Síntese dos aspectos gerais da coleção

\begin{tabular}{|l|l|l|l|l|c|}
\hline \multicolumn{1}{|c|}{ Critérios } & Exc & Bom & Reg & Rui & Observaçóes \\
\hline $\begin{array}{l}\text { Introdução e } \\
\text { desenvolvimento } \\
\text { dos conteúdos }\end{array}$ & $\mathbf{X}$ & & & & $\begin{array}{c}\text { Explicaçóes breves e concisas; apresenta } \\
\text { exemplos, o que auxilia na compreensão. }\end{array}$ \\
\hline $\begin{array}{l}\text { Organizaçáo dos } \\
\text { conteúdos }\end{array}$ & $\mathbf{X}$ & $\mathbf{X}$ & & $\begin{array}{c}\text { Mistura exercícios de outros subcapítulos } \\
\text { outros assuntos) em um mesmo subcapítulo. } \\
\text { Isso é interessante para revisar vários } \\
\text { subcapítulos e aplicar diferentes conhecimentos } \\
\text { ao mesmo tempo, mas talvez também fosse } \\
\text { interessante manter os exercícios separados por } \\
\text { subcapítulo para fixar melhor cada conteúdo. }\end{array}$ \\
\hline $\begin{array}{l}\text { Exercícios } \\
\text { propostos }\end{array}$ & $\mathbf{X}$ & & $\begin{array}{c}\text { Talvez fosse interessante haver mais estímulo } \\
\text { à interação entre a turma, além de apenas } \\
\text { solucionar exercícios no caderno. }\end{array}$ \\
\hline Linguagem & & & $\begin{array}{c}\text { Linguagem acessível ao público alvo: alunos de } \\
\text { ensino médio entre 14 e 18 anos. }\end{array}$ \\
\hline $\begin{array}{l}\text { Relação com a } \\
\text { fundamentaçáo } \\
\text { teórica }\end{array}$ & $\mathbf{X}$ & & $\begin{array}{l}\text { Todos os subcapítulos analisados estáo de } \\
\text { acordo com o abordado na fundamentaçáo } \\
\text { teórica, embora com uma abordagem mais } \\
\text { simples, sem uso de nomenclaturas. }\end{array}$ \\
\hline
\end{tabular}

Fonte: elaborado pelos autores

Em conclusão, a coleção de livros didáticos analisada compreende vários tópicos relevantes para a semântica através de uma linguagem acessível e conteúdos bem desenvolvidos e organizados. Além disso, os exercícios propostos, em sua maioria, estão bem relacionados aos assuntos abordados pelos respectivos capítulos e subcapítulos. Dessa forma, permite-se aos alunos que pratiquem os conhecimentos adquiridos pela teoria. Também, a maneira como cada assunto analisado foi tratado pelos livros didáticos está em consonância com o abordado pela fundamentação 
teórica deste trabalho. Sendo assim, é possível afirmar que o objetivo proposto por este trabalho, de realizar uma análise sobre uma coleção de livros didáticos para Ensino Médio a fim de avaliar a presença de conteúdos relacionados à semântica, foi atingido.

\section{Referências}

CANÇADO, Márcia. Manual de semântica: noções básicas e exercícios. 2 ed. São Paulo: Contexto, 2018.

CEREJA, William Roberto; MAGALHÃES, Thereza Cochar. Português: linguagens: volume 1: ensino médio. 5 ed. São Paulo: Atual, 2005a.

CEREJA, William Roberto; MAGALHÁES, Thereza Cochar. Português: linguagens: volume 2: ensino médio. 5 ed. São Paulo: Atual, 2005b.

CEREJA, William Roberto; MAGALHÁES, Thereza Cochar. Português: linguagens: volume 3: ensino médio. 5 ed. São Paulo: Atual, 2005c.

ECKERT, Kleber. A Ambiguidade. 2019. 14 slides. Material apresentado para a disciplina de Semântica e Pragmática no curso de Letras - Português do IFRS - Bento Gonçalves.

GERALDI, João Wanderley; ILARI, Rodolfo. Semântica. 11 ed. São Paulo: Ática, 2006.

MÜLLER, Ana Lucia de Paula; VIOTTI, Evani de Carvalho. Semântica formal.

In__. FIORIN, José Luiz. Introduçáo à Linguística II: princípios de análise. 5 ed. Sáo Paulo: Contexto, 2014. p. 137 - 159.

PIETROFORTE, Antonio Vicente Seraphim; LOPES, Ivã Carlos. Semântica lexical. In__. FIORIN, José Luiz. Introdução à Linguística II: princípios de análise. 5 ed.

São Paulo: Contexto, 2014. p. 111 - 132.

\section{APÊNDICE I}

Roteiro para Análise de Livros Didáticos

\section{1) Identificaçáo da coleçáo}
a. Autor(es):
b. Ano de publicação / edição:
c. Título / Nome da coleção:
d. Nome da editora:

\section{2) Identificaçáo do livro}
a. Série do Ensino Médio a que se destina:
b. Capítulo analisado: 


\section{3) Metodologia e Contextualizaçáo por subcapítulo}

a. Nome do subcapítulo analisado:

b. Comente a maneira como os conteúdos são introduzidos e desenvolvidos.

c. Há predominância de um conteúdo sobre o outro? O que está sendo trabalhado com mais ênfase?

d. Sobre os exercícios:

i. São condizentes com o material apresentado no livro?

ii. Há exercícios de repetição e memorização?

iii. Que tipo de exercício recebe maior ênfase?

e. Há incentivo no subcapítulo para que haja interação professor-aluno ou aluno-aluno nas atividades?

f.Como você avalia a profundidade da reflexão linguística proposta por meio dos exercícios?

g. A forma como o livro didático aborda os conteúdos tratados no subcapítulo é condizente com o que foi abordado pela fundamentação teórica?

4) Tabela síntese da análise da coleçáo

\begin{tabular}{|l|l|l|l|l|l|}
\hline \multicolumn{1}{|c|}{ Critérios } & Excelente & Bom & Regular & Ruim & Observaçáo \\
\hline $\begin{array}{l}\text { Introdução e desenvolvimento dos } \\
\text { conteúdos }\end{array}$ & & & & & \\
\hline Organização dos conteúdos & & & & & \\
\hline Exercícios Propostos & & & & & \\
\hline Linguagem & & & & & \\
\hline Relação com a fundamentação teórica & & & & & \\
\hline
\end{tabular}

